\title{
Comparison of base-isolated liquid storage tank models under bi-directional earthquakes
}

\author{
Sandip Kumar Saha*, Vasant A. Matsagar, Arvind K. Jain \\ Department of Civil Engineering, Indian Institute of Technology (IIT) Delhi, New Delhi, India; \\ *Corresponding Author: sandipksh@,civil.iitd.ac.in
}

Received 13 June 2013; revised 13 July 2013; accepted 20 July 2013

Copyright (C) 2013 Sandip Kumar Saha et al. This is an open access article distributed under the Creative Commons Attribution License, which permits unrestricted use, distribution, and reproduction in any medium, provided the original work is properly cited.

\begin{abstract}
Seismic response of ground supported baseisolated liquid storage tanks are evaluated under bi-directional earthquakes. The base-isolated liquid storage tanks are modeled using mechanical analogs with two and three lumped masses (Model 1 and Model 2). Two types of isolation systems, such as sliding system and elastomeric system, are considered for the present study. The isolation systems are modeled using Wen's equation for hysteretic isolation systems. Response of base-isolated liquid storage tanks, evaluated through two different modeling approaches, is compared. Both the models predict similar sloshing displacement. The effect of interaction between the mutually perpendicular seismic responses of the isolator is investigated for both the models. It is observed that interaction affects the peak seismic response of the base-isolated liquid storage tanks significantly, under the bi-directional earthquake components.
\end{abstract}

Keywords: Base Isolation; Bi-Directional; Earthquake; Interaction; Liquid; Sloshing; Tank

\section{INTRODUCTION}

Liquid storage tanks are one of the many important structures that demand greater safety measures against natural disaster like earthquake. Post failure consequences of industrial tanks sometimes trigger greater impact on human life through fire, chemical contamination, nuclear radiation etc. Besides these, water storage tanks are required to be maintained functional to serve the society even after devastating earthquake. Hence, protection of liquid storage tanks against earthquake is very essential. The dynamic behavior of liquid containing structures cannot be estimated by the same approach as for normal building structure, since the inside liquid influences its behavior largely. Therefore, appropriate modeling of the liquid storage tanks is essential for dynamic analysis and seismic response evaluation. Several research works reported in literature and guidelines in international codes and specifications are available for seismic analysis and design of liquid storage tanks [1-4]. Most of the design guidelines follow the lumped mass mechanical analog to model the cylindrical liquid storage tanks. A brief review of the international codes on seismic analysis of liquid storage tanks can be found in [5]. However, conventional design approach, without sophisticated vibration control devices, many times cannot provide sufficient protection against seismic forces.

Several researchers have reported the benefits of the passive vibration control strategy using base isolation technique, as an efficient seismic protection method of structures [6-9]. There are two broad categories of base isolation systems, which are in use throughout the world, such as sliding system and elastomeric bearing. Malhotra [10], Shrimali and Jangid [11] and many other researchers reported the use of base isolation for enhancing seismic performance of liquid storage tanks. Shrimali and Jangid [12] investigated the effect of seismic response interaction on the performance of base-isolated liquid storage tanks. However, they had only considered the sliding bearing as isolation system. Jadhav and Jangid [13] compared the performance of different isolation systems for seismic protection of liquid storage tanks. They had investigated the performance of liquid storage tanks under bi-directional near-fault earthquake. However, the effect of the interaction between the orthogonal hysteretic responses of the isolators was not studied.

In most of the above research works, the base-isolated liquid storage tank has been modeled using the mechanical analog proposed by Haroun and Housner [14]. This model considers the tank wall flexibility while calculating the seismic response. Another mechanical analog, proposed earlier by Housner [4], is also extensively 
used for modeling of liquid storage tanks for dynamic analysis. The major difference of these two models is the number of lumped masses into which the liquid column is divided. Whereas, the two-mass model is convenient for designers to use due to ease, the three-mass model apparently predicts the seismic response more accurately. Hence, the choice of an appropriate modeling approach is crucial.

Herein, the base-isolated liquid storage tank is modeled using both, the two- and three mass models and the interaction of isolator hysteretic response is investigated under bi-directional earthquakes. Two different types of isolation systems, namely sliding system and elastomeric bearing, are considered for the present study. The major objectives of this study are: 1) to compare the seismic response using two different lumped mass models of base-isolated liquid storage tanks subjected to bi-directional earthquakes; and 2) to investigate the effect of interaction between the two mutually perpendicular hysteretic displacement components of isolation system.

\section{MODELING OF BASE-ISOLATED LIQUID STORAGE TANKS}

The ground supported cylindrical base-isolated liquid storage tank is modeled using two different lumped mass mechanical analogs: 1) two-mass model (Model 1) proposed by Housner [4] and 2) three-mass model (Model 2) proposed by Haroun and Housner [14]. Figure 1 shows the two different models of the base-isolated liquid storage tanks. A brief detail of the models are provided here.

\subsection{Two-Mass Model (Model 1)}

This model divides the liquid column into two layers.
The upper layer, called convective mass, is considered to vibrate relative to the tank wall and resulting in the sloshing phenomenon, whereas the bottom layer, called impulsive mass, vibrates with the tank as rigid body and experience same earthquake acceleration as the base. The impulsive mass predominately contributes to the base shear and overturning moment of the tank. In this model, the convective mass $\left(m_{c}\right)$ of the liquid is considered to be connected to the solid tank wall with certain stiffness $\left(k_{c}\right)$ at a height $H_{c}$, whereas the impulsive mass $\left(m_{i}\right)$ is connected rigidly to the tank wall at a height $H_{i}$. In the present study, only tanks with circular plan geometry are considered; hence, hereafter all the discussion will be restricted to circular tank only.

Figure 1(a) shows the schematic diagram of the tank model with the parameters mentioned above where total height of the liquid inside the tank is denoted by $H$ and radius for circular tank is denoted by $R$.

The stiffness of the spring attached to the convective mass $\left(k_{c}\right)$ as per this model is given by

$$
k_{c}=1.84\left(m_{c} g / R\right) \tanh (1.84 H / R)
$$

where, $g$ is the gravitational acceleration. Detailed expressions for the other parameters of the tank model are given in [4].

\subsection{Three-Mass Model (Model 2)}

In this model, Haroun and Housner [14] proposed an additional rigid mass $\left(m_{\mathrm{r}}\right)$, acting at a height of $H_{\mathrm{r}}$, that rigidly moves along with the tank wall. The impulsive mass $\left(m_{\mathrm{i}}\right)$, acting at a height of $H_{\mathrm{i}}$, is assumed in contact with the tank wall through a spring with stiffness $k_{\mathrm{i}}$. Similarly, the convective or sloshing mass $\left(m_{\mathrm{c}}\right)$, acting at a height of $H_{\mathrm{c}}$, is assumed in contact with the tank wall through a spring with stiffness $k_{\mathrm{c}}$. They also considered a
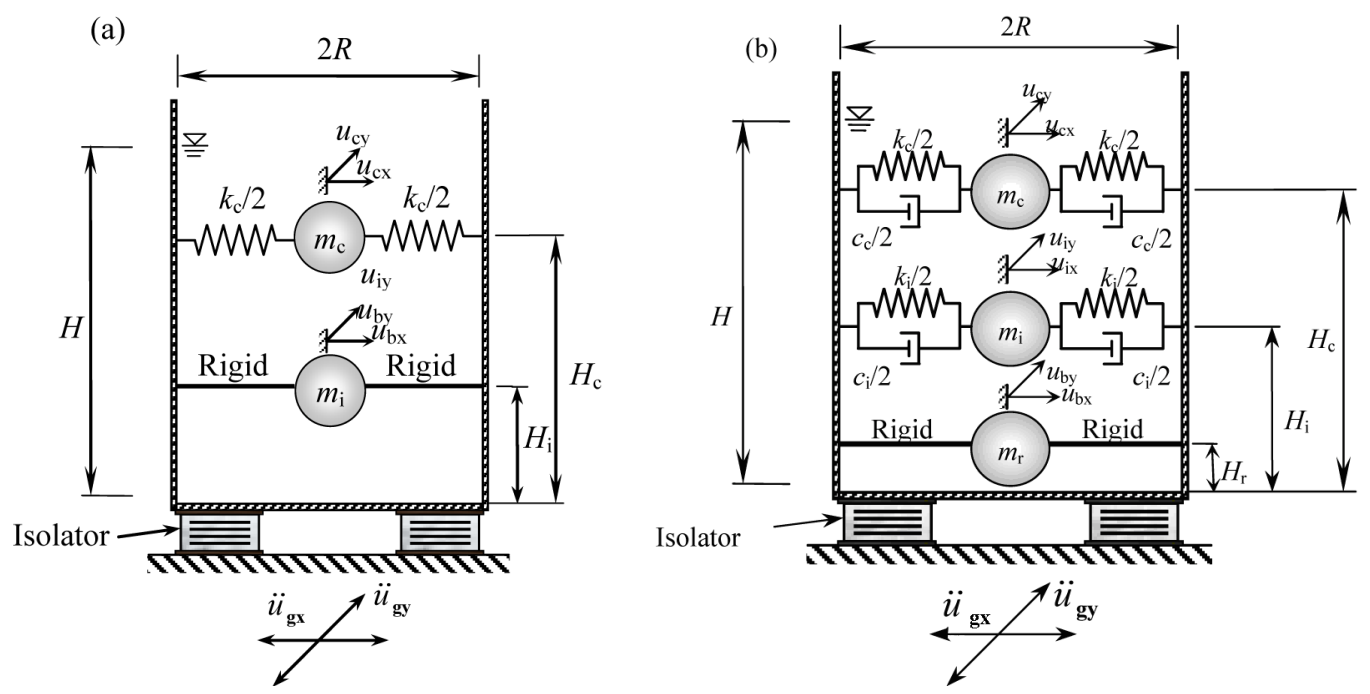

Figure 1. Schematic diagrams of the base-isolated liquid storage tanks: (a) Two-mass model (Model 1) and (b) Three-mass model (Model 2). 
small amount of damping, for impulsive and sloshing mass.

Figure 1(b) shows the schematic diagram of Model 2 with all the parameters. The stiffness of the springs attached to the convective mass $\left(k_{c}\right)$ is same as the Model 1; however, the stiffness of the spring attached to the impulsive mass $\left(k_{i}\right)$ is given by

$$
k_{i}=E m_{i} / \rho_{s}(P / H)^{2}
$$

where, $E$ and $\rho_{s}$ are the modulus of elasticity and density of the tank wall material, respectively; and $P$ is a dimensionless parameter. The parameters of the tank are given in graphical form in [14]. The mathematical expressions of the parameters can be obtained from [11].

\section{MODELING OF ISOLATION SYSTEM}

For the present study, a non-linear model [15] is used to characterize the hysteretic force-deformation behavior of the isolation system, as shown in Figure 2. The behavior of the isolator is considered identical in both $x$-and $y$ directions. The restoring forces developed in these isolation systems for bi-directional excitation are given by

$$
\left\{\begin{array}{l}
F_{b x} \\
F_{b y}
\end{array}\right\}=\alpha\left[\begin{array}{ll}
k_{e} & 0 \\
0 & k_{e}
\end{array}\right]\left\{\begin{array}{l}
x_{b} \\
y_{b}
\end{array}\right\}+(1-\alpha) F_{y}\left\{\begin{array}{l}
Z_{x} \\
Z_{y}
\end{array}\right\}
$$

where, $F_{\mathrm{y}}$ denotes yield strengths of the bearing in both $x$ - and $y$-directions; $\alpha$ represents the ratio of post to pre-yield stiffness; $k_{e}$ denotes pre-yield stiffness of the bearing in both $x$ - and $y$-directions. Here, $Z_{x}$ and $Z_{y}$ denote non-dimensional hysteretic displacement components satisfying the following non-linear first order differential equation [16].

$$
q\left\{\begin{array}{l}
\ddot{Z}_{x} \\
\ddot{Z}_{y}
\end{array}\right\}=\left[\begin{array}{ll}
C_{11} & C_{12} \\
C_{21} & C_{22}
\end{array}\right]\left\{\begin{array}{l}
\dot{x}_{b} \\
\dot{y}_{b}
\end{array}\right\}
$$

where, $C_{11}=A-\beta \operatorname{sgn}\left(\dot{x}_{b}\right)\left|Z_{x}\right| Z_{x}^{n-1}-\tau Z_{x}^{n}$, $C_{12}=-\beta \operatorname{sgn}\left(\dot{y}_{b}\right)\left|Z_{y}\right| Z_{x}^{n-1}-\tau Z_{x} Z_{y}$,

$C_{21}=-\beta \operatorname{sgn}\left(\dot{x}_{b}\right) Z_{y} Z_{y}^{n-1}-\tau Z_{y} Z_{x}$, and $C_{22}=A-\beta \operatorname{sgn}\left(\dot{y}_{b}\right)\left|Z_{y}\right| Z_{y}^{n-1}-\tau Z_{y}^{n}$.

In Eq.4, $q$ denotes isolator yield displacement in both $x$ - and $y$-directions; $A, \beta$ and $\tau$ are dimensionless parameters; and parameter $n$ is an integer constant, which controls smoothness of the transition from elastic to plastic response. These dimensionless parameters $A, \beta, \tau$ and $n$ can be chosen in such a way that the model represents either a sliding system or an elastomeric system.

\section{EQUATIONS OF MOTION}

The governing equations of motion of the base-isolated liquid storage tank under bi-directional earthquake excitation are written in the matrix form as

$$
[\bar{M}]\{\ddot{X}\}+[\bar{C}]\{\dot{X}\}+[\bar{K}]\{X\}+\{F\}=-[\bar{M}][r]\left\{\ddot{u}_{g}\right\}
$$

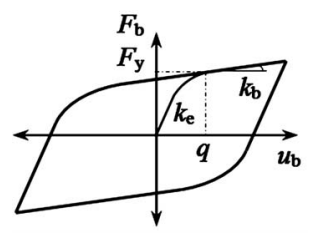

Figure 2. Non-linear Force-deformation behavior of the isolation system.

where, $\{X\}$ is the relative displacement vector; $\{F\}$ is the hysteretic restoring force vector; $[\bar{M}],[\bar{C}]$ and $[\bar{K}]$ are the mass, damping and stiffness matrices of the system, respectively; $\left\{\ddot{u}_{g}\right\}=\left\{\ddot{u}_{g x} \ddot{u}_{g y}\right\}^{\mathrm{T}}$ is the earthquake ground acceleration vector and $[r]$ is the influence coefficient matrix. The order of the vectors and matrices depend on the model of the liquid storage tank.

For Model 1, the mass matrix, $[\bar{M}]$, damping matrix, $[\bar{C}]$ and stiffness matrix, $[\bar{K}]$ can be written as

$$
\begin{aligned}
& {[\bar{M}]=\left[\begin{array}{cccc}
m_{c} & m_{c} & 0 & 0 \\
m_{c} & M & 0 & 0 \\
0 & 0 & m_{c} & m_{c} \\
0 & 0 & m_{c} & M
\end{array}\right]} \\
& {[\bar{C}]=\operatorname{diag}\left[\begin{array}{llll}
c_{c} & c_{b} & c_{c} & c_{b}
\end{array}\right]} \\
& {[\bar{K}]=\operatorname{diag}\left[\begin{array}{llll}
k_{c} & k_{b} & k_{c} & k_{b}
\end{array}\right]}
\end{aligned}
$$

where, $M=m_{\mathrm{c}}+m_{\mathrm{i}}$. The displacement and hysteretic restoring vectors are given as

$$
\begin{aligned}
& \{X\}=\left\{\begin{array}{llll}
x_{c} & x_{b} & y_{c} & y_{b}
\end{array}\right\}^{\mathrm{T}} \\
& \{F\}=\left\{\begin{array}{ll}
0 & (1-\alpha) F_{y} Z_{x} \quad 0 \quad(1-\alpha) F_{y} Z_{y}
\end{array}\right\}^{\mathrm{T}}
\end{aligned}
$$

where, $x_{c}=\left(u_{c x}-u_{b x}\right)$ and $y_{c}=\left(u_{c y}-u_{b y}\right)$ are the displacements of the convective mass relative to the bearing displacement in $x$ - and $y$-directions, respectively; $x_{b}=$ $\left(u_{b x}-u_{g x}\right)$ and $y_{b}=\left(u_{b y}-u_{g y}\right)$ are bearing displacements relative to the ground in $x$ - and $y$-directions, respectively. The influence coefficient matrix takes the following form

$$
[r]=\left[\begin{array}{cccc}
0 & 1 & 0 & 0 \\
0 & 0 & 0 & 1
\end{array}\right]^{\mathrm{T}}
$$

For Model 2, the mass, $[\bar{M}]$, damping, $[\bar{C}]$ and stiffness, $[\bar{K}]$ matrices are given as

$$
[\bar{M}]=\left[\begin{array}{llllll}
m_{c} & 0 & m_{c} & 0 & 0 & 0 \\
0 & m_{i} & m_{i} & 0 & 0 & 0 \\
m_{c} & m_{i} & M & 0 & 0 & 0 \\
0 & 0 & 0 & m_{c} & 0 & m_{c} \\
0 & 0 & 0 & 0 & m_{i} & m_{i} \\
0 & 0 & 0 & m_{c} & m_{i} & M
\end{array}\right]
$$




$$
\begin{aligned}
& {[\bar{C}]=\operatorname{diag}\left[\begin{array}{llllll}
c_{c} & c_{i} & c_{b} & c_{c} & c_{i} & c_{b}
\end{array}\right]} \\
& {[\bar{K}]=\operatorname{diag}\left[\begin{array}{llllll}
k_{c} & k_{i} & k_{b} & k_{c} & k_{i} & k_{b}
\end{array}\right]}
\end{aligned}
$$

where, $M=m_{c}+m_{i}+m_{b}$. The displacement and hysteretic restoring vectors are given as

$$
\begin{gathered}
\{X\}=\left\{\begin{array}{llllll}
x_{c} & x_{i} & x_{b} & y_{c} & y_{i} & y_{b}
\end{array}\right\}^{\mathrm{T}} \\
\{F\}=\left\{\begin{array}{llllll}
0 & 0 & (1-\alpha) F_{y} Z_{x} & 0 & 0 & (1-\alpha) F_{y} Z_{y}
\end{array}\right\}^{\mathrm{T}}
\end{gathered}
$$

where, $x_{\mathrm{c}}=\left(u_{c x}-u_{b x}\right)$ and $y_{\mathrm{c}}=\left(u_{c y}-u_{b y}\right)$ are the displacements of the convective mass relative to the bearing displacement in $x$ - and $y$-directions, respectively; $x_{i}=\left(u_{i x}\right.$ $\left.-u_{b x}\right)$ and $y_{i}=\left(u_{i y}-u_{b y}\right)$ are the displacements of the impulsive mass relative to the bearing displacements in $x$ and $y$-directions, respectively; $x_{b}=\left(u_{b x}-u_{g x}\right)$ and $y_{b}=\left(u_{b y}\right.$ $-u_{g y}$ ) are bearing displacements relative to the ground in $x$ - and $y$-directions, respectively. The influence coefficient matrix takes the following form

$$
[r]=\left[\begin{array}{llllll}
0 & 0 & 1 & 0 & 0 & 0 \\
0 & 0 & 0 & 0 & 0 & 1
\end{array}\right]^{\mathrm{T}}
$$

Numerical solution of Eq.5 is obtain using Newmark's step-by-step integration technique, adopting linear variation of acceleration between two time steps, to determine the seismic response of the base-isolated liquid storage tank. Once the displacement and acceleration quantities are known, for Model 2, the base shears $\left(V_{b x}\right.$ and $\left.V_{b y}\right)$ and overturning moments $\left(M_{b x}\right.$ and $\left.M_{b y}\right)$ in either direction are

$$
\begin{gathered}
V_{b x}=m_{c} u_{c x}+m_{i} u_{i x}+m_{r} u_{b x} \\
V_{b y}=m_{c} u_{c y}+m_{i} u_{i y}+m_{r} u_{b y} \\
M_{b x}=m_{c} u_{c x}+m_{i} u_{i x} H_{i}+m_{r} u_{b x} H_{r} \\
M_{b y}=m_{c} u_{c y}+m_{i} u_{i y} H_{i}+m_{r} u_{b y} H_{r}
\end{gathered}
$$

For Model 1, appropriate masses, accelerations and heights are to be taken for the calculation of the base shear and overturning moment.

\section{NUMERICAL STUDIES}

Ground supported cylindrical steel storage tanks are considered for the present study. Two different tank configurations are taken namely broad and slender. In Table 1, the geometrical properties of the cylindrical steel tanks are summarized. The thickness of the tank wall, used for Model 2, is denoted by $t$. The slenderness ratio $(S)$ is determined by $H / R$. The liquid inside the tank is considered as water (mass density $=1000 \mathrm{~kg} / \mathrm{m}^{3}$ ). For Model 2 , the damping of the convective $\left(\xi_{c}\right)$ and impulsive $\left(\xi_{i}\right)$ masses are assumed as $0.5 \%$ and $2 \%$, respectively. In the present study, two different types of the isolators are studied, such as sliding system and elastomeric bearing. To model isolator force-deformation behavior, the dimensionless parameters of the Wen's model are chosen appropriately as given in Table 2. Total eight earthquake time histories, comprising of near-fault and far-fault ground motions, are considered. The details of the earthquake acceleration inputs are given in Table 3 . The sliding system is characterized by the isolation time period $\left(T_{b}\right)$ and friction coefficient $(\mu)$. Whereas, the elastomeric bearing is commonly characterized by its isolation time period $\left(T_{b}\right)$ and damping $\left(\xi_{b}\right)$, yield displacement $(q)$ and the normalized yield strength $\left(F_{y} / W\right)$, where, $W=M g$ is the total weight of the structure. For the present study, $T_{b}$ and $\mu$ for the sliding system is assumed as $2 \mathrm{sec}$ and 0.05 , respectively. The elastomeric bearing properties are assumed as, $T_{b}=2 \mathrm{sec}, \xi_{b}=0.1$ and $F_{y} / W=0.05$.

The isolator force-deformation for the sliding system and elastomeric bearing are plotted in Figure $\mathbf{3}$ for El-Centro earthquake. Model 1 represents the two mass mechanical analog, whereas Model 2 represents three mass mechanical analog. The isolator restoring forces $\left(F_{b x}\right.$ and $\left.F_{b y}\right)$ are presented in normalized form in terms of the total weight of the structure $(W)$. It is observed that the Wen's model can represent the force-deformation behavior of two different types of isolators, when the parameters are chosen appropriately.

\subsection{Comparison of Seismic Response Obtained from Two Models}

The peak seismic response quantities of base-isolated liquid storage tanks using the two models are compared herein. The important seismic response quantities considered are the base shears $\left(V_{b x}\right.$ and $\left.V_{b y}\right)$, base displacements $\left(x_{b}\right.$ and $\left.y_{b}\right)$, sloshing displacements $\left(x_{c}\right.$ and $\left.y_{c}\right)$ and overturning moments $\left(M_{b x}\right.$ and $\left.M_{b y}\right)$. For the sliding system, the isolation time period $\left(T_{b}\right)$ is taken as $2 \mathrm{sec}$ and the friction coefficient $(\mu)$ is taken as 0.05 . The isolation time period $\left(T_{b}\right)$, the isolation damping $\left(\xi_{b}\right)$ and the normalized yield strength $\left(F_{y} / W\right)$ of the elastomeric bearing are taken as $2 \mathrm{sec}, 0.1$ and 0.05 , respectively. Two types of tank configurations, such as broad $(S=0.6)$ and

Table 1. Properties of the cylindrical tanks.

\begin{tabular}{cccc}
\hline Type of tank & $S=H / R$ & $H(\mathrm{~m})$ & $t / R$ \\
\hline Broad tank & 0.6 & 14.6 & 0.004 \\
Slender tank & 1.85 & 11.3 & 0.004 \\
\hline
\end{tabular}

Table 2. Parameters of the Wen's model.

\begin{tabular}{cccccc}
\hline Isolator & $A$ & $\beta$ & $\tau$ & $n$ & $q(\mathrm{~cm})$ \\
\hline Sliding system & 1 & 0.9 & 0.1 & 2 & 0.025 \\
Elastomeric bearing & 1 & 0.5 & 0.5 & 2 & 2.5 \\
\hline
\end{tabular}


Table 3. Details of the earthquake acceleration time histories.

\begin{tabular}{|c|c|c|c|c|c|}
\hline S1. no. & Event; record & Notation & Component & Direction & $\mathrm{PGA}^{\mathrm{a}}(\mathrm{g})$ \\
\hline \multirow{2}{*}{1} & \multirow{2}{*}{ Imperial Valley, 1940; El-Centro } & \multirow{2}{*}{ El-Centro } & Normal $(\mathrm{N})$ & $x$ & 0.26 \\
\hline & & & Parallel (P) & $y$ & 0.31 \\
\hline \multirow{2}{*}{2} & \multirow{2}{*}{ Imperial Valley, 1979; Array ${ }^{\#}$} & \multirow{2}{*}{ Imperial ${ }^{\#}$} & Normal (N) & $x$ & 0.36 \\
\hline & & & Parallel (P) & $y$ & 0.54 \\
\hline \multirow{2}{*}{3} & \multirow{2}{*}{ Imperial Valley, 1979; Array ${ }^{\#}$} & \multirow{2}{*}{ Imperial $^{\#} 7$} & $\operatorname{Normal}(\mathrm{N})$ & $x$ & 0.45 \\
\hline & & & Parallel (P) & $y$ & 0.33 \\
\hline \multirow{2}{*}{4} & \multirow{2}{*}{ Loma Prieta, 1989; LGPC } & \multirow{2}{*}{ Loma Prieta } & Normal $(\mathrm{N})$ & $x$ & 0.61 \\
\hline & & & Parallel (P) & $y$ & 0.56 \\
\hline \multirow{2}{*}{5} & \multirow{2}{*}{ Northridge, 1992; Rinaldi } & \multirow{2}{*}{ Rinaldi } & Normal $(\mathrm{N})$ & $x$ & 0.87 \\
\hline & & & Parallel (P) & $y$ & 0.38 \\
\hline \multirow{2}{*}{6} & \multirow{2}{*}{ Northridge, 1992; Sylmar } & \multirow{2}{*}{ Sylmar } & Normal (N) & $x$ & 0.72 \\
\hline & & & Parallel (P) & $y$ & 0.58 \\
\hline \multirow{2}{*}{7} & \multirow{2}{*}{ Landers, 1992; Lucerne Valley } & \multirow{2}{*}{ Lucerne } & Normal $(\mathrm{N})$ & $x$ & 0.71 \\
\hline & & & Parallel (P) & $y$ & 0.64 \\
\hline \multirow{2}{*}{8} & \multirow{2}{*}{ Kobe, 1995; JMA } & \multirow{2}{*}{ Kobe } & Normal (N) & $x$ & 0.60 \\
\hline & & & Parallel (P) & $y$ & 0.82 \\
\hline
\end{tabular}

${ }^{\mathrm{a}} \mathrm{PGA}=$ Peak ground acceleration.
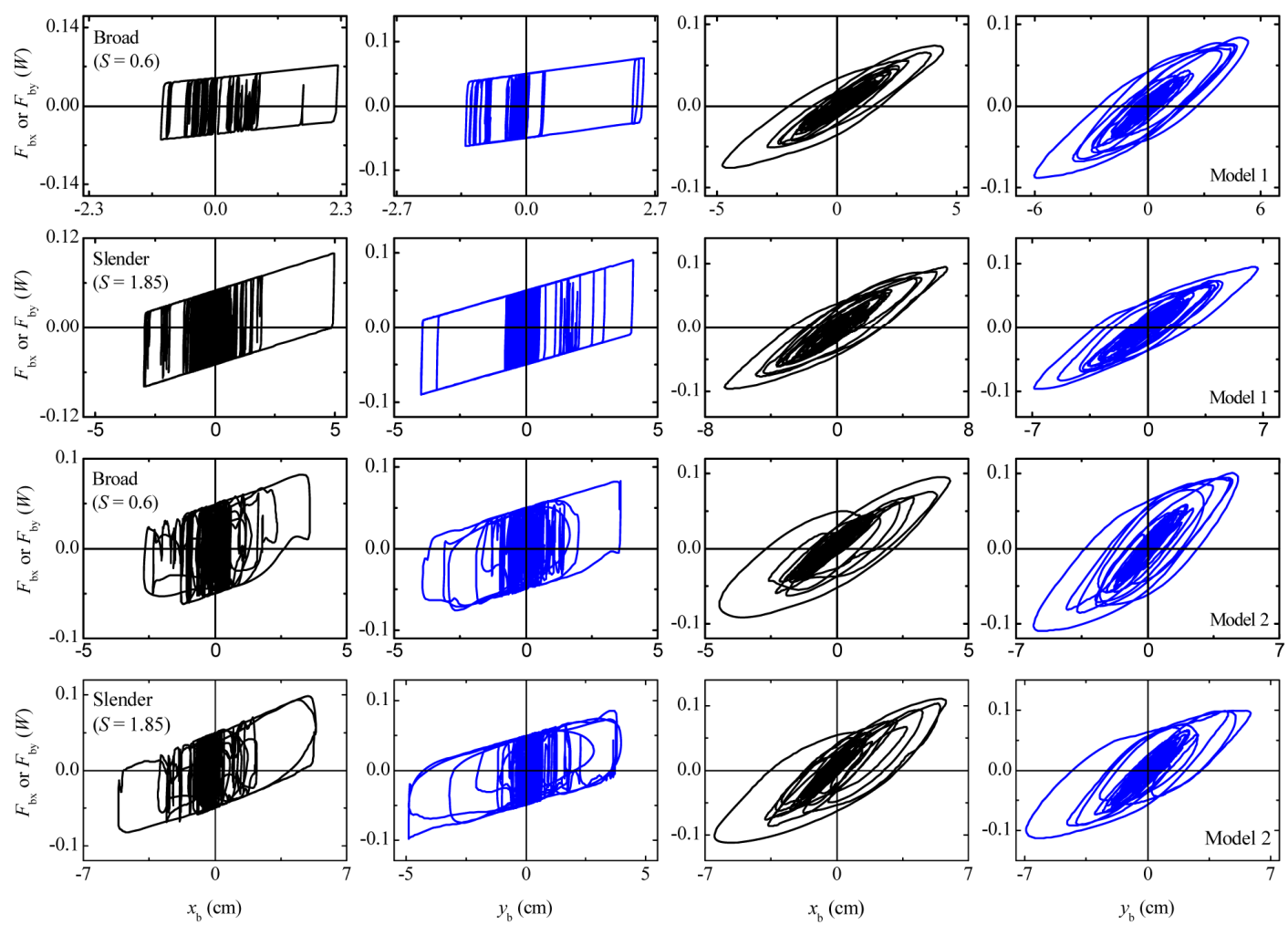

(a) Sliding system
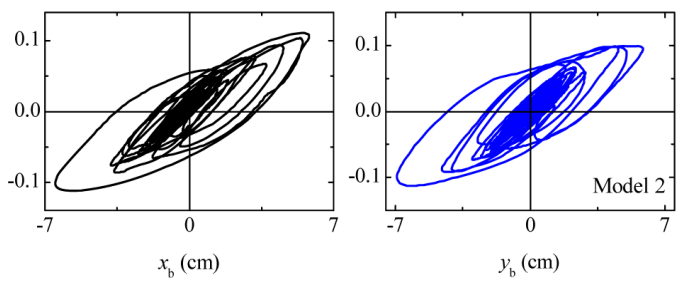

(b) Elastomeric bearing

Figure 3. Isolator force-deformation behavior under El-Centro earthquake (for sliding system: $T_{b}=2 \sec$ and $\mu$ $=0.05$; for elastomeric bearing: $T_{b}=2 \mathrm{sec}, \xi_{b}=0.1, q=2.5 \mathrm{~cm}, F_{y} / W=0.05$ ).

slender $(S=1.85)$, are studied. Figures 4 and $\mathbf{5}$ show the response time histories under El-Centro earthquake for the broad and slender tank configurations in $x$ - and $y$ directions, respectively. The base shear and the overturn- 

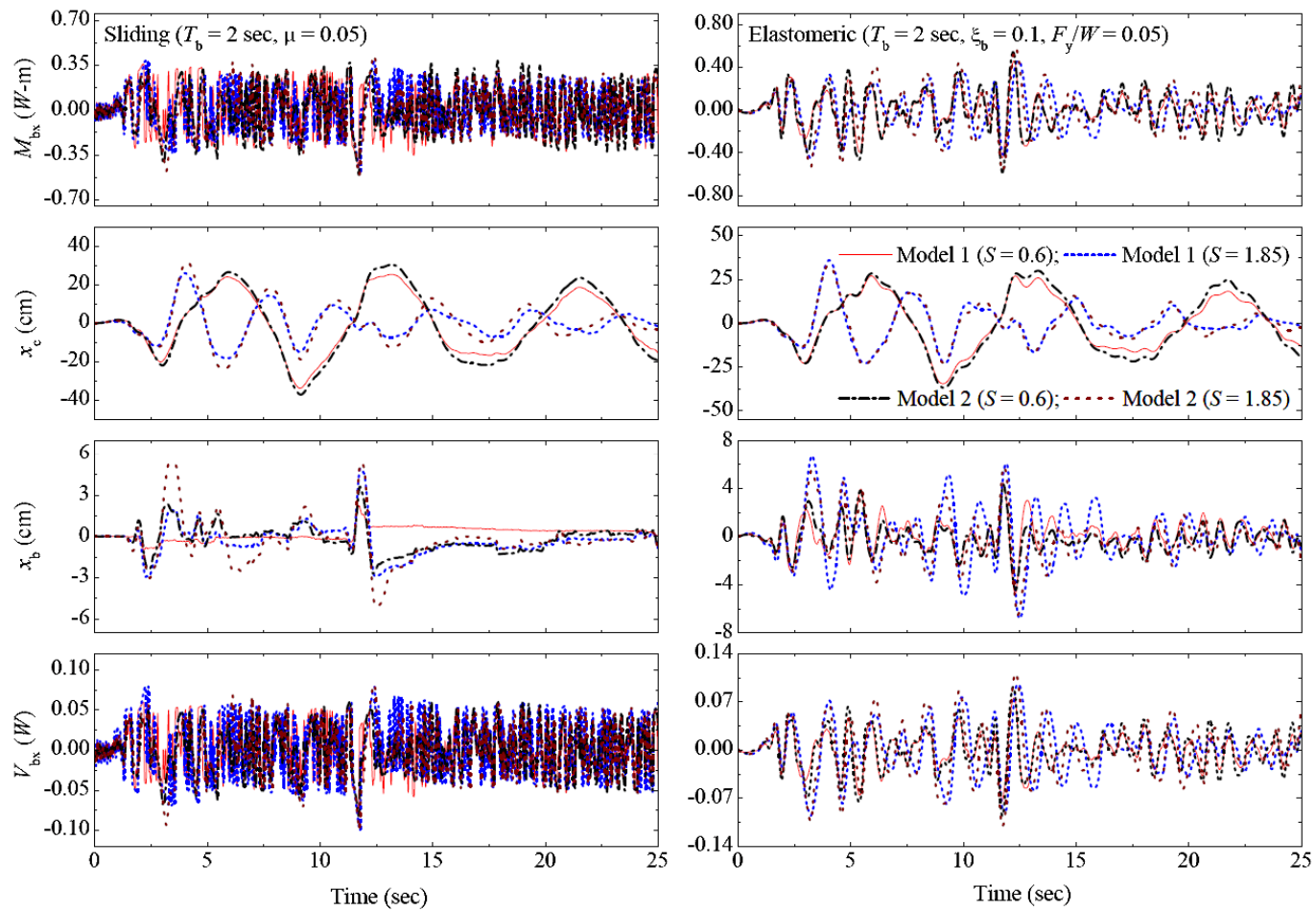

Figure 4. Time history of the response quantities along $x$ - direction under bi-directional El-Centro earthquake.
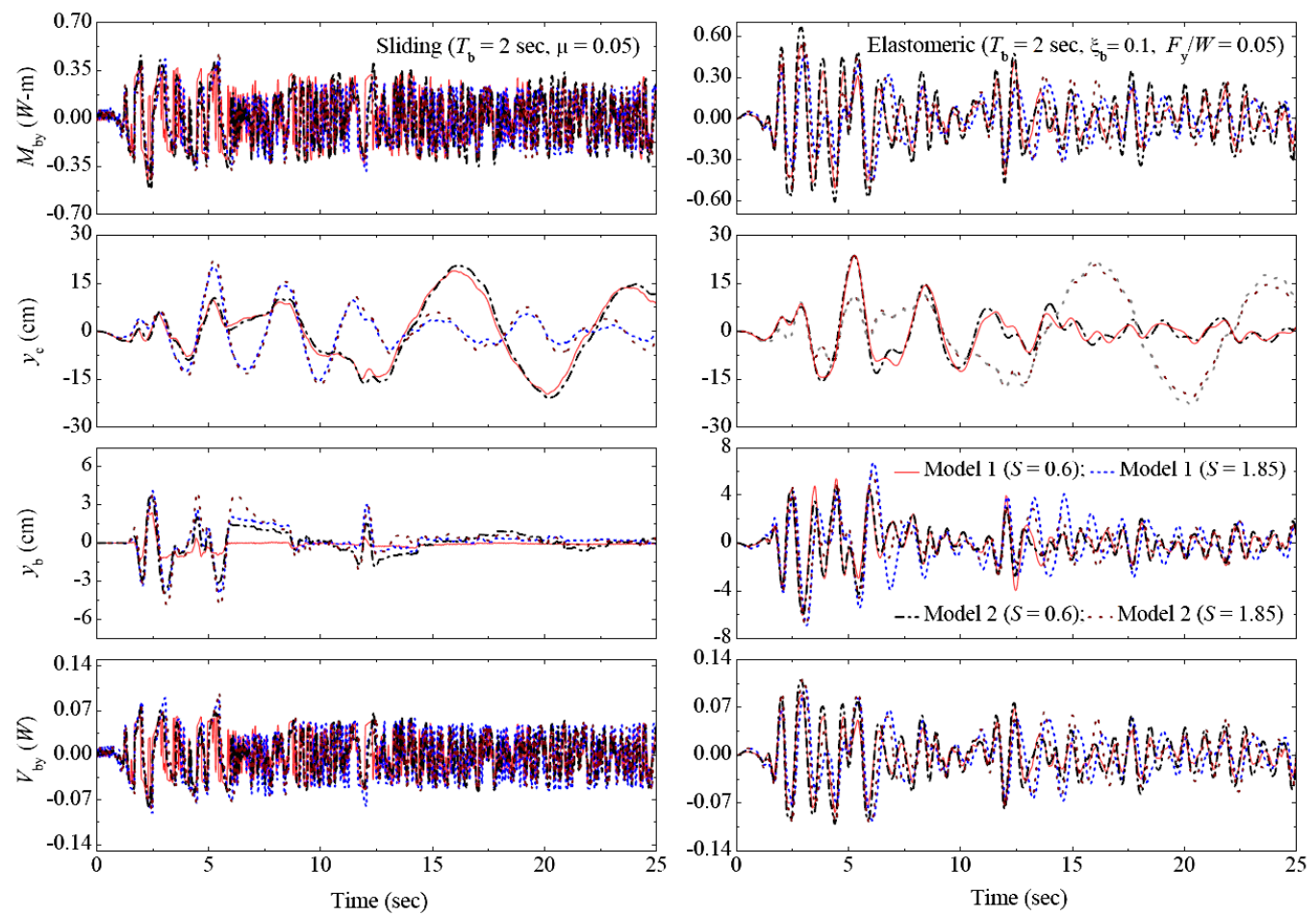

Figure 5. Time history of the response quantities along $y$-direction under bi-directional El-Centro earthquake.

ing moments are presented as normalized with respect to total weight of the structure $(W)$.

It can be observed that there are considerable differences in the seismic response obtained by the two dif- ferent modeling approaches for the liquid storage tanks. However, the sloshing displacement is not much affected by the modeling approaches. This phenomenon is also evident from Eq.1. The sloshing frequency is not influ- 


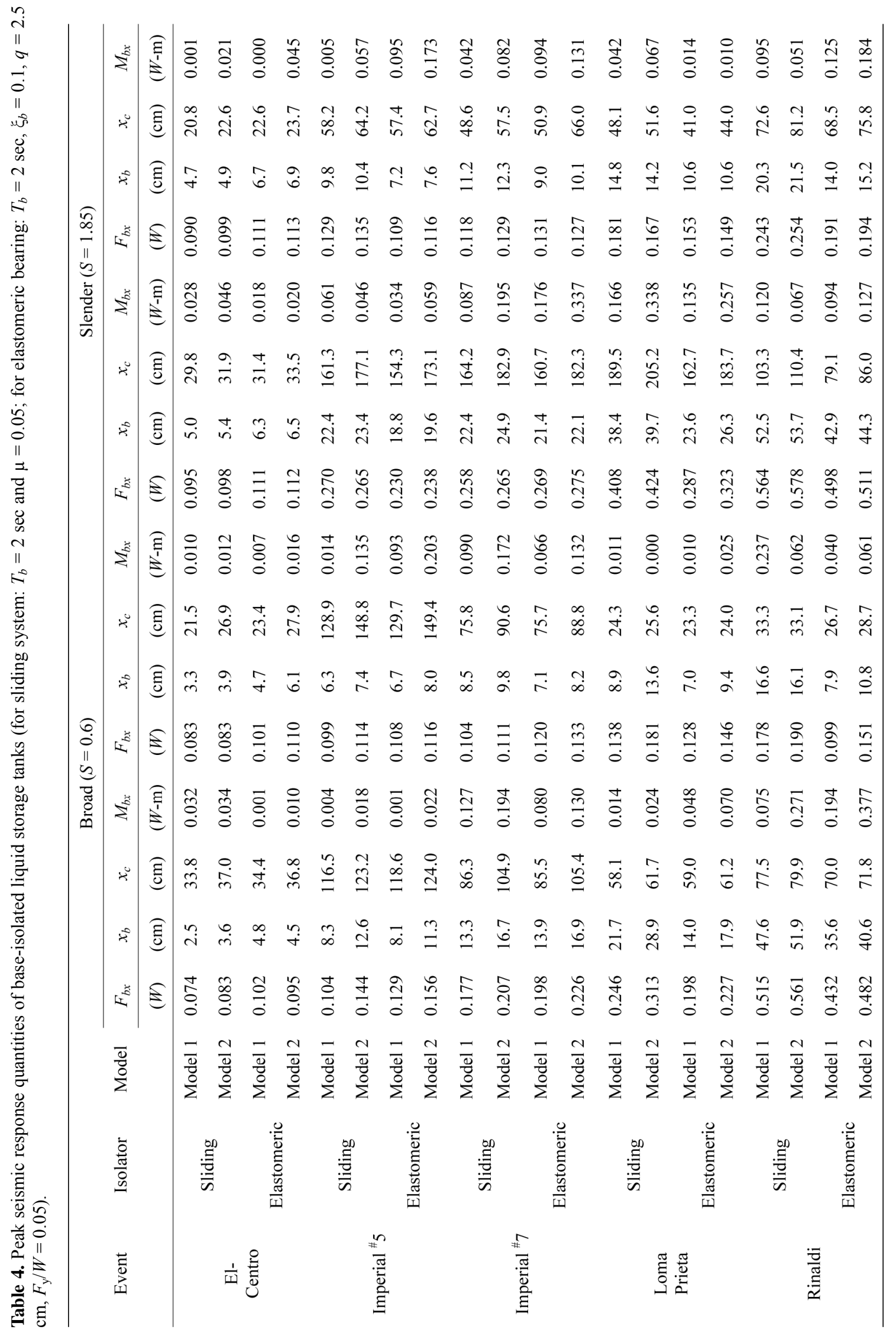




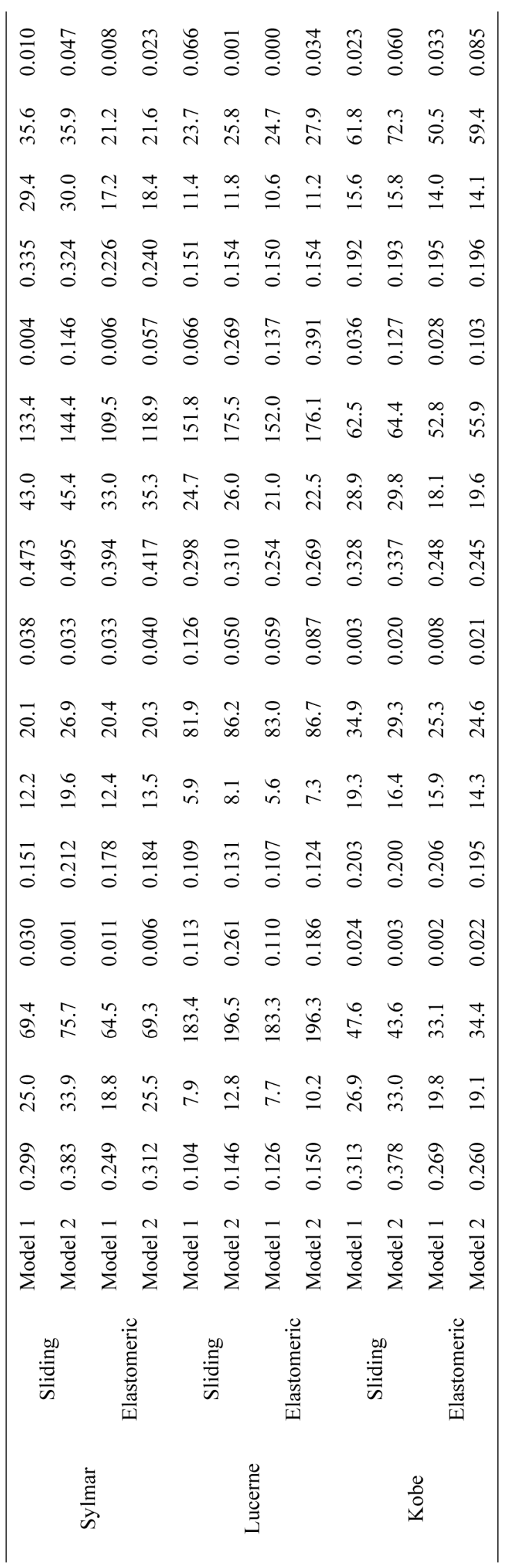



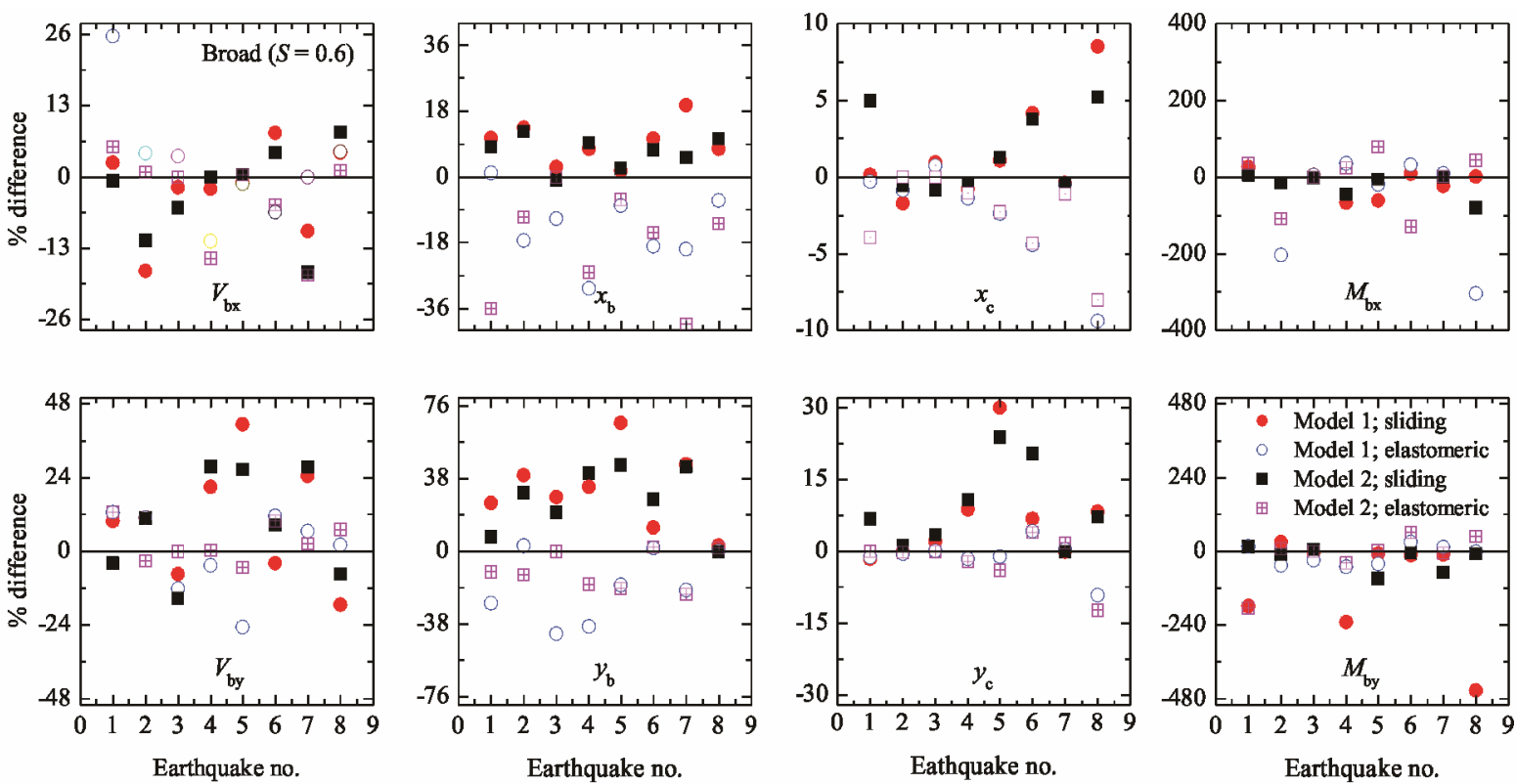

Figure 6. Effect of seismic response interaction on broad tank (for sliding system: $T_{b}=2 \mathrm{sec}$ and $\mu=0.05$; for elastomeric bearing: $\left.T_{b}=2 \mathrm{sec}, \xi_{b}=0.1, q=2.5 \mathrm{~cm}, F_{y} / W=0.05\right)$.
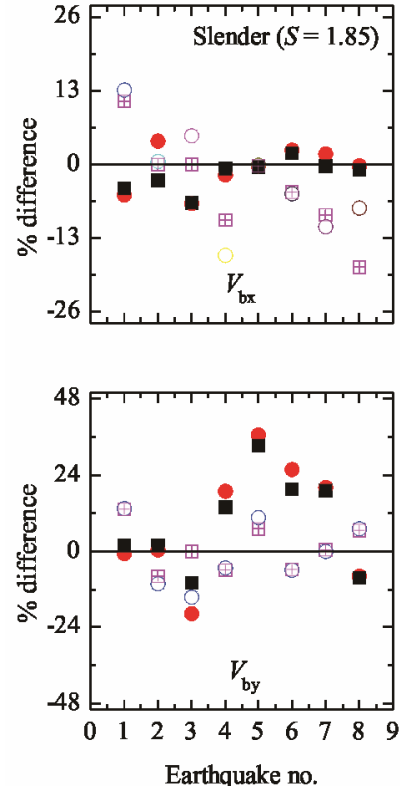
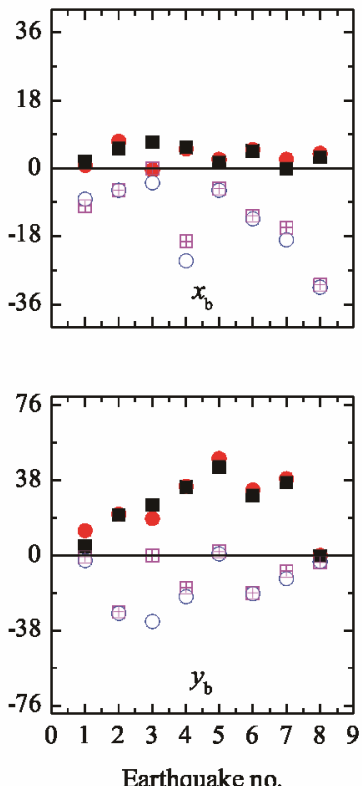
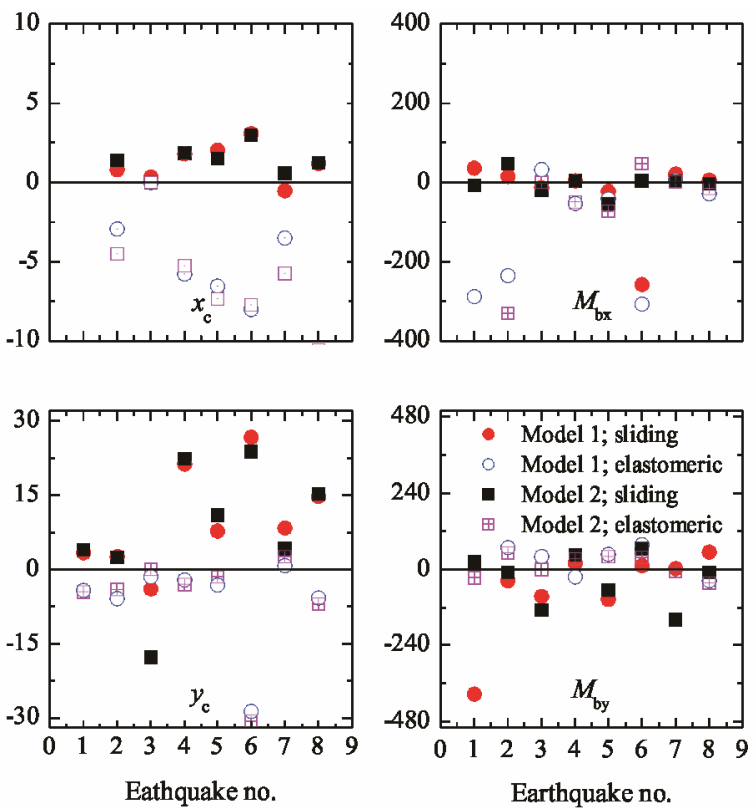

Figure 7. Effect of seismic response interaction on slender tank (for sliding system: $T_{b}=2 \mathrm{sec}$ and $\mu=0.05$; for elastomeric bearing: $\left.T_{b}=2 \mathrm{sec}, \xi_{b}=0.1, q=2.5 \mathrm{~cm}, F_{y} / W=0.05\right)$.

enced by the material properties of the tank wall, and they are the same for both the tank models. Hence, their seismic response time histories are also not affected by the modeling approaches. However, with the inclusion of an additional rigid mass the impulsive frequency changes in Model 2. As a result, the base shear, base displacement and overturning moment differ with the modeling approaches. It is further observed that the computed base shear and overturning moment of the liquid storage tank, isolated by sliding system, contains significant high frequency response, which is also observed for building like structure [17].

The peak seismic response quantities of the broad and slender tanks are compared in Table $\mathbf{4}$ for all the earthquakes given in Table 3. It can be observed that the Model 1 underestimate the peak seismic response of the base-isolated liquid storage tanks. However, peak sloshing displacements, computed using the two different 
modeling approaches, are not affected for both the tank configurations. Furthermore, the difference in the seismic response, obtained through two different modeling approaches, is more for broad tanks as compared to slender tanks. It can also be observed that most of the seismic response quantities are increased when the tank is baseisolated using sliding system as compared to case when the tank is base-isolated using elastomeric bearing, except the base displacements $\left(x_{b}\right.$ and $\left.y_{b}\right)$.

\subsection{Effect of Interaction on the Peak Seismic Response}

The effect of interaction between two mutually perpendicular hysteretic displacement components of the isolator under bi-directional earthquake excitation is studied. For the sliding system, the isolation time period $\left(T_{b}\right)$ is taken as $2 \mathrm{sec}$ and the friction coefficient $(\mu)$ is taken as 0.05 . The isolation time period $\left(T_{b}\right)$, the isolation damping $\left(\xi_{b}\right)$ and the normalized yield strength $\left(F_{y} / W\right)$ of the elastomeric bearing are taken as $2 \mathrm{sec}, 0.1$ and 0.05 , respectively. Two types of tank configurations, such as broad $(S=0.6)$ and slender $(S=1.85)$, are studied. Figures 6 and 7 show the percentage difference of the peak seismic response quantities for broad and slender tank configurations, respectively. For example, \% difference in the base displacement in $x$-direction $\left(x_{b}\right)$ is calculated as

$$
\% \text { difference in } x_{b}=\frac{\left(x_{b}\right)_{\text {interaction }}-\left(x_{b}\right)_{\text {no-interaction }}}{\left(x_{b}\right)_{\text {interaction }}} \times 100
$$

where, $\left(x_{b}\right)_{\text {interaction }}$ and $\left(x_{b}\right)_{\text {no-interaction }}$ indicates the peak base displacement when interaction is considered and not considered, respectively. Here, zero percentage indicates that there is no effect of interaction on the seismic response. A negative percentage indicates that the peak seismic response is more when response interaction is not considered.

It is observed that both the models of the base-isolated liquid storage tanks are showing similar trend to predict the effect of response interaction of broad and slender tanks. It is also observed that the effect of interaction is most significant for base displacement. Sloshing displacement is less affected by the interaction. Base shear and overturning moment are also influenced by the consideration of the interaction. The effect of the interaction in bi-directional seismic response is observed to be marginally more in the broad tanks as compared to the slender tanks, and the seismic response along $y$-direction is more influenced by the interaction than along $x$-direction. It is further observed that the consideration of the interaction affect the seismic response differently in case of sliding system and elastomeric bearing. The effect of interaction in case of the sliding system is more pronounced than in case of the elastomeric bearing. For sliding system, the base displacement increases when the interaction is considered. However, for elastomeric bearing interaction reduces the base displacement.

\section{CONCLUSIONS}

Seismic response of base-isolated liquid storage tanks is investigated under bi-directional earthquakes. The liquid storage tank is modeled using a) two mass and b) three mass mechanical analogs. Two different isolation systems, namely sliding system and elastomeric bearing, are considered. A comparison of the important response quantities, obtained through two different modeling approaches of the tank, is carried out. The effects of the interaction, between the two mutually perpendicular hysteretic displacement components of the isolator, on the response, are also studied. Following are the major conclusions drawn from the present study.

1) The two-mass model (Model 1) and three-mass model (Model 2) of the base-isolated liquid storage tanks estimate almost the same sloshing displacement. However, base shear, base displacement and overturning moment are underestimated by the two-mass model as compared to the three-mass model.

2) The base shear and overturning moment of the liquid storage tank, isolated by sliding system, contains significant high frequency components.

3) The difference in the peak response, obtained through Model 1 and Model 2, is more for broad tanks.

4) Peak seismic response quantities, except base displacements, are increased when the tank is base-isolated using sliding system as compared to case when the tank is base-isolated using elastomeric bearing.

5) Consideration of interaction between two mutually perpendicular hysteretic displacement components of the isolator significantly affects the peak response of the base-isolated liquid storage tanks.

6) Effect of the interaction under bi-directional earthquake is predicted similarly by the Model 1 and Model 2 .

\section{REFERENCES}

[1] ACI 350.3 (2006) Seismic design of liquid containing concrete structures. American Concrete Institute, Farmington Hills.

[2] API 650 (1998) Welded storage tanks for oil storage. American Petroleum Institute Standard, Washington DC.

[3] AWWA D-100 (1996) Welded steel tanks for water storage. American Water Works Association, Colorado.

[4] Housner, G.W. (1963) The dynamic behavior of water tanks. Bulletin of Seismological Society of America, 53, 381-387. 
[5] Jaiswal, O.R., Rai, D.C. and Jain, S.K. (2007) Review of seismic codes on liquid-Containing tanks. Earthquake Spectra, 23, 239-260. doi:10.1193/1.2428341

[6] Buckle, I.G. and Mayes, R.L. (1990) Seismic isolation history, application and performance-A world view. Earthquake Spectra, 6, 161-201. doi:10.1193/1.1585564

[7] Jangid, R.S. and Datta, T.K. (1995) Seismic behavior of base-isolated buildings: A state-of-the-art review. Structures and Buildings, 110, 186-203. doi:10.1680/istbu.1995.27599

[8] Ibrahim, R.A. (2008) Recent advances in non-linear passive vibration isolators. Journal of Sound and Vibration, 314, 371-452. doi:10.1016/j.jsv.2008.01.014

[9] Matsagar, V.A. and Jangid, R.S. (2008) Base isolation for seismic retrofitting of structures. Practice Periodical on Structural Design and Construction, ASCE, 13, 175-185. doi:10.1061/(ASCE)1084-0680(2008)13:4(175)

[10] Malhotra, P.K. (1997) Method for seismic base isolation of liquid-storage tanks. Journal of Structural Engineering, ASCE, 123, 113-116. doi:10.1061/(ASCE)0733-9445(1997)123:1(113)

[11] Shrimali, M.K. and Jangid, R.S. (2004) Seismic analysis of base-isolated liquid storage tanks. Journal of Sound and Vibration, 275, 59-75. doi:10.1016/S0022-460X(03)00749-1
[12] Shrimali, M.K. and Jangid, R.S. (2002) Seismic response of liquid storage tanks isolated by sliding bearings. Engineering Structures, 24, 909-921. doi:10.1016/S0141-0296(02)00009-3

[13] Jadhav, M.B. and Jangid, R.S. (2006) Response of baseisolated liquid storage tanks to near-fault motions. Structural Engineering and Mechanics, 23, 615-634.

[14] Haroun, M.A. and Housner, G.W. (1981) Seismic design of liquid storage tanks. Journal of Technical Councils of ASCE, 107, 91-207.

[15] Park, Y.J., Wen, Y.K. and Ang, A.H.-S. (1986) Random vibration of hysteretic systems under bi-directional ground motions. Earthquake Engineering and Structural Dynamics, 14, 543-557. doi:10.1002/eqe.4290140405

[16] Wen, Y.K. (1976) Method for random vibration of hysteretic system. Journal of the Engineering Mechanics Division, ASCE, 102, 249-263.

[17] Matsagar, V.A. and Jangid, R.S. (2004) Influence of isolator characteristics on the response of base-isolated structures. Engineering Structures, 26, 1735-1749. doi:10.1016/j.engstruct.2004.06.011 